\section{Ecitse}

${ }^{1}$ Department of Respiratory Diseases, University Hospitals Leuven, Leuven, Belgium ${ }^{2}$ Department of Psychiatry, University Hospitals Leuven, Leuven, Belgium

${ }^{3}$ Department of Hematology, University Hospitals Leuven, Leuven, Belgium

\section{Correspondence to} Dr N E De Maeyer, Department of Respiratory Diseases, University Hospitals Leuven, Herestraat 49, Leuven 3000, Belgium; nikolaas.demaeyer@ uzleuven.be

Prior publication: The case was presented as a poster at the annual meeting of the Belgian Society of Pneumology (05-12 2015, Brussels Belgium) and won the second prize in the J.C. Yernault award. https:// www.bvp-sbp.org/index.php/nl/ awards-fellowships/jcynl

Received 9 March 2016 Revised 5 June 2016

Accepted 7 June 2016

Published Online First

7 July 2016

CrossMark

To cite: De Maeyer NE, Van Lommel S, Devos T, et al.

Thorax 2016;71:967-968.

\title{
A surprising cause of polycythaemia
}

\author{
N E De Maeyer, ${ }^{1}$ S Van Lommel, ${ }^{2}$ T Devos, $^{3}$ B Buyse, ${ }^{1}$ K Nackaerts ${ }^{1}$
}

\section{CASE PRESENTATION}

A 48-year-old man was referred to the outpatient clinic because of fatigue and an elevated haemoglobin level of $19.4 \mathrm{~g} / \mathrm{dL}$. His relevant medical history only revealed psychosis. He had quit cigarette smoking for several years. His daily medication schedule consisted of valproic acid $1500 \mathrm{mg}$, quetiapine $400 \mathrm{mg}$ and lormetazepam $1 \mathrm{mg}$ daily. There were no clinical abnormalities besides a body mass index of $28.3 \mathrm{~kg} / \mathrm{m}^{2}$.

Since primary erythrocytosis was not excluded initially, venesections were performed three times. Meanwhile, diagnostic work-up took place. Serum erythropoietin levels and V617F JAK-2 mutation were normal. Red blood cell mass nuclear scintigraphy showed an absolute elevation in red blood cell mass. Bone marrow examination, chest X-ray, abdominal ultrasound and functional cardiopulmonary evaluation were non-diagnostic.

Because of fatigue and significant weight gain, a polysomnography was performed, showing moderate obstructive sleep apnoea with an apnoea-hypopnoea index of 19/hour of sleep. Oxygen desaturation below $90 \%$ occurred during $74 \mathrm{~min}$, with an absolute minimum of $86 \%$. Following regulations in our country, CPAP therapy was not reimbursed. Therefore, we opted for conservative treatment with weight loss, which was hard to achieve. His polycythaemia persisted despite his efforts.

\section{QUESTION}

What is the missing element in his medical record and what would be your next investigation to complete the diagnosis? 


\section{ANSWER}

After a more profound history taking, we found out that he was a regular water pipe smoker, smoking about $90 \mathrm{~min} /$ day. Carboxyhaemoglobin ratio proved to be $13.7 \%$ on arterial blood gas analysis (normal range for heavy smoker: 7\%-9\%). A patient-tailored smoking cessation programme was offered and the patient succeeded in quitting smoking with the aid of a trained psychologist and an electronic cigarette. Following smoking cessation, haemoglobin levels returned within normal limits (figure 1).

\section{DISCUSSION}

Secondary polycythaemia has a wide range of possible aetiologies, among which smoker's polycythaemia has been discovered decades ago. ${ }^{1}$ In the Western world, smoking is usually understood as cigarette or cigar smoking. However, water pipe smoking has increasing user rates in Western countries. ${ }^{2}$

In our case, only a more profound history taking revealed his actual smoking habits. The patient saw no harm in his smoking behaviour. Yet, several epidemiological and other studies suggest otherwise. ${ }^{3}$ The significant lowering of haemoglobin concentration and expired carbon monoxide measurements after successful smoking cessation, suggest a causal link between water pipe smoking and polycythaemia in our patient. In literature, we found two case reports with similar findings to ours. ${ }^{45}$

Contributors SVL, TD, BB and KN treated the patient. NEDM performed the literature research. All authors wrote and corrected the manuscript in a substantial way. BB and $\mathrm{KN}$ contributed equally to the manuscript.

Competing interests None declared.

Patient consent Obtained.

Provenance and peer review Not commissioned; externally peer reviewed.

\section{REFERENCES}

1 Smith JR, Landaw SA. Smokers' polycythemia. N Engl J Med 1978;298:6-10.

2 Primack BA, Freedman-Doan P, Sidani JE, et al. Sustained waterpipe tobacco smoking and trends over time. Am J Prev Med 2015;49:859-67.

3 El-Zaatari ZM, Chami HA, Zaatari GS. Health effects associated with waterpipe smoking. Tob Control 2015;24(Suppl 1):i31-43.

4 Tadmor T, Mishchenko E, Polliack A, et al. Hookah (narghile) smoking: a new emerging cause of secondary polycythemia. Am J Hematol 2011;86:719-20.

5 Bonadies N, Tichelli A, Rovó A. When water does not clear the smut from the smoke. BMJ Case Rep Published 18 Oct 2013. doi:10.1136/bcr-2013-200665

Evolution of hemoglobin $(\mathrm{g} / \mathrm{dL})$ and expired $\mathrm{CO}(\mathrm{ppm})$ concentration

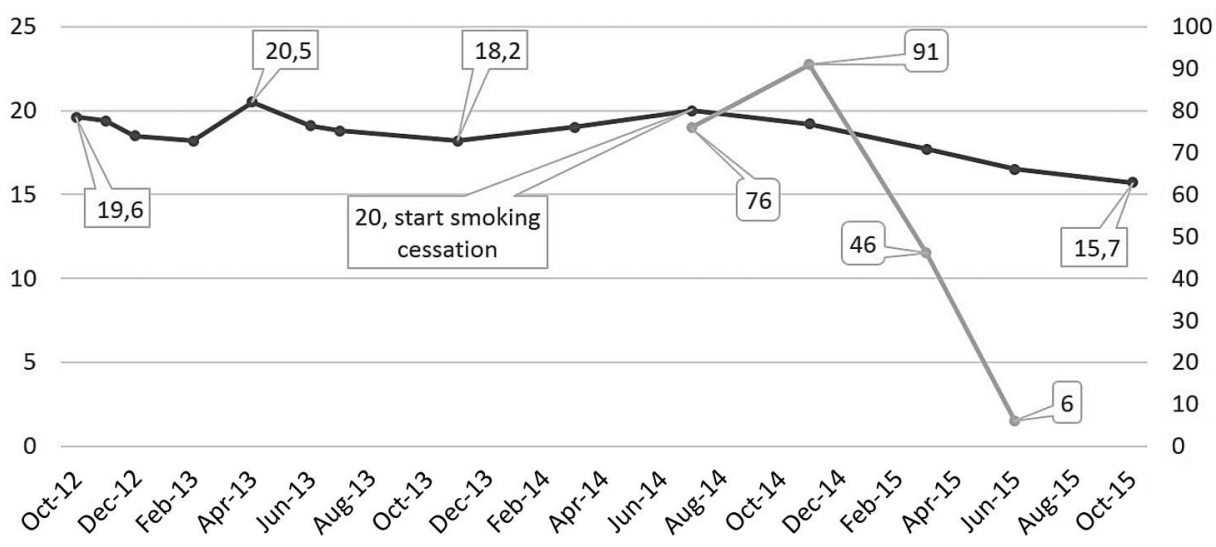

Figure 1 Evolution of serum haemoglobin ( $\mathrm{g} / \mathrm{dL}$, black line) and expired carbon monoxide (ppm, grey line) concentration over time. 